\title{
A mulher pentecostal na luta por terra: Uma análise do assentamento Luiza Ferreira
}

\author{
Fabio Alves Ferreira \\ Universidade de Pernambuco \\ Milene Almeida \\ Estudante de Serviço Social \\ Universidade de Pernambuco
}

Resumo: Esse texto propõe a análise do papel da mulher pentecostal na luta pela conquista da terra, que reside no Assentamento Luiza Ferreira, localizado em São Lourenço da Mata, em Pernambuco. Percebemos que a participação da mulher pentecostal tem sido fundamental na consolidação do assentamento. Pudemos perceber que a sua militância política e religiosa não é divergente. Pelo contrário, há uma hermenêutica própria gestada no cotidiano de luta. Utilizamos o método de entrevistas semi-estruturadas e observação participante. Entrevistamos doze mulheres da Igreja Assembleia de Deus que vivem no Assentamento.

Palavras-chave: Mulher pentecostal; MST; Luta por terra. 


\title{
The pentecostal women in the struggle for land: A settlement analysis Luiza Ferreira
}

\begin{abstract}
This paper proposes the analysis of the social role of Pentecostal women in the struggle for land, who lives in the settlement Luiza Ferreira, in São Lourenço da Mata city, in Pernambuco. We realize that the participation of Pentecostal women have been instrumental in the consolidation of settlement. Their political and religious militancy is not divergent. On the contrary, there is a hermeneutic gestated in the struggle daily. We use the method of semi-structured interviews and participant observation. We interviewed twelve women living in the settlement.
\end{abstract}

Key words: Pentecostal woman; MST; conflict over land.

\section{Las mujeres pentecostales en la lucha por la tierra: Un análisis del asentamiento Luisa Ferreira}

Resúmen: En este trabajo se propone el análisis del papel de las mujeres pentecostales en la lucha por la tierra, que se encuentra en el asentamiento Luisa Ferreira, ubicada en Sao Lourenco da Mata, Pernambuco. Nos damos cuenta de que la participación de las mujeres pentecostales han sido fundamentales en la consolidación del asentamiento. Nos dimos cuenta de que su militancia política y religiosa no es divergente. Por el contrario, hay una hermenéutica gestado en la lucha cotidiana. Utilizamos el método de entrevistas semiestructuradas y observación participante. Entrevistamos a doce mujeres de la Iglesia Asamblea de Dios que viven en el asentamiento.

Palabras clave: mujer pentecostal; MST; Lucha por la tierra. 


\section{Introdução}

Este artigo visa compreender as ações de mulheres camponesas pentecostais no Assentamento Luiza Ferreira. São mulheres que lutaram insistentemente, junto ao Movimento dos Trabalhadores Rurais Sem Terra (MST a partir de agora), para adquirir um lote de terra que, segundo elas, representa a possibilidade de uma nova vida: com sua fé, com sua agricultura, com o conhecimento político e com o sonho de ter, finalmente, a casa própria. Esta casa reiteradamente é reportada em suas falas como "a casa dos sonhos".

Para compreender a atuação destas mulheres e suas expectativas, realizamos várias inserções naquele lugar. Dormimos no assentamento, realizamos refeições juntos com os/as militantes, participamos dos cultos e, assim, tivemos a oportunidade de realizar observação participante, aplicar entrevistas semi-estruturadas e entrevistas narrativas. As entrevistas Semiestruturada e Narrativa nos permitiram o conhecimento das dinâmicas sociais no interior do Assentamento entre os agentes: pentecostais, dirigentes do MST, líderes de cooperativas, moradores do engenho desde antes da ocupação. Isso nos permitiu ver a reconstrução conjunta de fatos da história do assentamento; a dinâmica da interação entre todos estes indivíduos; e como as opiniões, em torno da vivência coletiva no assentamento, são produzidas (FLICK, 2009). No caso, a observação participante foi fundamental no sentido de que permitiu aos pesquisadores uma familiarização com aspectos locais, com a linguagem, bem como perceber elementos omitidos pelos entrevistados (BAUER, 2002). Estas técnicas de pesquisa foram, no contexto, se desvelando como necessárias para uma aproximação do mundo da vida daquelas mulheres camponesas e pentecostais. Pudemos compreender os códigos e significados que desnudavam o seu mundo e mostravam o horizonte capaz de ser modificado por suas inserções no presente.

Imediatamente percebemos que o assentamento é complexo e distancia-se de uma leitura apressada de que os movimentos sociais, em Particular o MST, são homogêneos (BURITY, 2008; MUTZENBERG, 2011). Pelo contrário, os assentamentos tendem a ser bastante heterogêneos no que se refere à disputa pela organização interna (FERREIRA, 2013; NOGUEIRA, 2006). É bem certo que, na identificação de uma existência social permeada de incertezas e restrições em vários âmbitos da vida, as diferenças religiosas, ideológicas e estéticas sofrem transformações, adaptações e ajustam-se umas às outras, formando um discurso maior, no qual todas as diferenças se percebem enredadas por uma lógica de identificação, capaz de mobilizar seus sentimentos, temporariamente, numa direção (LACLAU, 2005; HOWARTH \& STAVRAKAKIS, 2000). Em outras palavras, no momento inicial da instauração de um acampamento, os militantes tendem a ser focados prioritariamente na conquista da terra, nas orientações do MST, nas novas formas de organização, no aprendizado necessário para viver nesse novo ambiente. Posteriormente, as diferenças emergirão como elementos importantes de serem distinguidos naquele contexto. 
Sabendo que as diferenças tendem ser minoradas, no período inicial dos assentamentos, o próprio MST oferece um discurso, em torno do qual os camponeses homens e mulheres, crianças e idosos se juntam num ato monódico e demorado de reivindicação. É importante para o sucesso do movimento, que ele tenha atores convictos de sua ação. Para isso, há um investimento intelectual e didático para que essa incorporação de novos capitais seja realizada no reconhecimento do princípio de que seu cotidiano é cortado por uma desigualdade que não é natural. Isto é, umas das bases do MST é o reconhecimento de um agenciamento possível a quem sempre foi negado. Processo bastante semelhante aos das religiões pentecostais nas periferias das cidades. Hipótese já levantada e constatada pelo Instituto de Pesquisas Econômicas (IPEA), e pelas publicações seguintes de Jesse Souza (2010; 2012). Entre os cidadãos mais empobrecidos cresce-se as religiões pentecostais e nela "a crença na própria capacidade passa a ser um valor máximo" (SOUZA, 2013, p. 155). A religião, neste caso, é construída numa perspectiva de alteração do lugar de subalternidade. Ação semelhante à do MST. Esse é um traço elementar que deve ser reconhecido, a nosso ver, para compreensão das ações das mulheres pentecostais no MST.

Para compreender essa realidade, lançamos mão da teoria agônica de Chantal Mouffe e, algumas discussões temáticas, da perspectiva dos estudos de subalternidade. A primeira mirada assume como premissa constitutiva do social: (i) A realidade é heterogênea e a totalidade implica num conjunto de identidades diversas ligadas por um signo que fecha o sentido temporariamente; (ii) a construção do povo se dá pela demanda como unidade mínima de análise. Demandas insatisfeitas tornam-se equivalentes na reivindicação de algo maior. Esse conjunto passa a representar o todo. Uma particularidade torna-se hegemônica e representa todas as demais na reivindicação de sua petição (LACLAU, 2005; LACLAU, MOUFFE, 1985). A segunda mirada concebe que os lugares de violência se desvelam pela naturalidade que seu enraizamento cultural concebe às práticas sociais. Nestes espaços é possível perceber como a mulher é colocada como "ator não credível" quando relacionado à legitimidade do homem. Supõe-se ainda que são práticas institucionalizadas desde a colonização.

Em uma sociedade democrática como o Brasil, o MST é rotulado por vários atores sociais como a mídia, grupos políticos, donos de terra e outros, com a pecha de perturbador da ordem pública. Caracterizado como um movimento responsável pelo desalinho nas funções institucionais e a sociedade civil. Tais signos são responsáveis por promover uma visão de que os militantes são pessoas desocupadas e violentas (COLETTI, 2005). Os conflitos são manifestações visíveis de que há várias ideias, várias formas de viver.

Para o MST, as políticas relacionadas à soberania alimentar e incentivo à agricultura familiar não representam as necessidades dos camponeses. Os conflitos instaurados por este movimento social são manifestações visíveis deste projeto alternativo de lidar com as demandas do campo rural brasileiro. Expressa, portanto, interesse antagônico ao projeto hegemônico. Sobre questões como estas, Mouffe (2003) argumenta que o lugar social é inevitavelmente plural. Portanto os antagonismos são esperados, uma vez que se têm atores e sujeitos diferentes. Logo, eles vão se associar ou se dissociar conforme os seus interesses que estão pautados pela demanda que os empurra ou os afasta de determinados grupos. O social é o campo da heterogeneidade. Portanto, qualquer regra, qualquer padrão consiste na hegemonia do grupo que conseguiu 
angariar mais aliados. Neste sentido, tal ideia se tornou hegemônica. O antagonismo é o reconhecimento de que a ordem vigente está limitada pela possibilidade de a identidade emular-se sobre o mundo de forma diferente. A impossibilidade de totalização de um sentido único da realidade.

O crescimento do pentecostalismo nos contextos rurais, que é o recorte deste texto, é indício das mudanças nas práticas sociais de fieis e igrejas pentecostais. Já tem sido notado que o pentecostalismo e a luta por terra desvelam a plasticidade desse fenômeno religioso e, desde esta perspectiva, o diálogo com a cultura política dos movimentos sociais (FERREIRA, 2013). Isso avança para novas configurações da mudança social religiosa, uma vez que os primeiros estudiosos das religiões pentecostais acentuaram sua rigidez como marca fulcral: moralismo; imobilismo político e fixidez do papel da mulher na aba da vontade do homem. Além dessas características, a ascese pentecostal tradicional foi sempre destacada: negação da fruição da vida nas festividades culturais brasileiras (CAMPOS, 2005; CORTEN, 1996; D’EPINAY, 1970; MARIANO, 1999). Todo esse conjunto de informes pentecostais tem sido desaprumado em prol de novos costumes que revela um pentecostalismo paradoxal e itinerante na direção do diálogo.

\section{Conhecendo o assentamento Luiza Ferreira: Uma história na perspectiva da mulher religiosa}

Em 30 de março de 2010 o MST fez um levantamento de parte das terras pertencentes à Usina Bulhões, e concluiu que deveria ser desapropriada, uma vez que não estava dentro dos critérios contidos na Constituição Federal, sobre propriedade privada. A Constituição Federal de 1988, no artigo 170, e a Lei $\mathrm{n}^{\mathrm{o}}$ 8629, de 25 de fevereiro de 1993, artigo $9^{\circ}$, têm o objetivo de explicitar os preceitos constitucionais da função social da terra. Dentre eles, defendem o aproveitamento racional e adequado; a utilização adequada dos recursos naturais disponíveis e preservação do meio ambiente; a observância das disposições que regulam as relações de trabalho; e exploração que favoreça o bem-estar dos proprietários e dos trabalhadores. Segundo o MST, suas ações de ocupação da terra estão baseadas no propósito de assegurar estes princípios norteadores. Assim ocorreu a ocupação das terras na qual funcionava a Usina Bulhões, no município de São Lourenço da Mata. Convêm destacar que embora o local seja geograficamente pertencente a São Lourenço, os moradores têm a sua sociabilidade desenvolvida com o município de Moreno. Nele, escoam as suas produções agrícolas.

No dia 7 de abril de 2010, ocorreu a ocupação com 23 famílias que moraram e trabalharam para o dono do engenho. Algumas destas pessoas já moravam na cidade e com demissões frequentes e sinais evidentes de possível falência da Usina, procuraram a liderança do MST para ajudá-las. Neste momento congregou-se em torno do discurso de permanência na terra: as famílias que ainda viviam nas dependências do Engenho; as famílias que compunham uma pluriatividade (trabalhavam no campo e na cidade para complementar suas rendas); outras famílias desempregadas das cidades vizinhas que foram atraídas para o movimento por convite dos ex-trabalhadores da Usina Bulhões.

Uma característica que perpassa todos aqueles "sem-terra" é a de que em algum momento de suas histórias assinalaram uma ligação com a zona rural. 
Justificavam uma familiaridade com este espaço social por meio da infância vivida no campo; tiveram pais que foram camponeses1; parentes camponeses, etc. Outro aspecto observado regularmente, nas falas daqueles militantes, é o de que estavam em busca de um lugar para viver e trabalhar que representasse a superação de uma situação de privação anterior. Neste sentido, ao passo que o aumento de reivindicações indica um descredito das instituições asseguradoras da dignidade do cidadão (BURITY, 2009), o assentamento significa, para eles, a possibilidade de alteração de sua vida. (MARTINS, 2009; MAGALHAES, 2003; COSTA \& BERGAMASCO, 2003; SIGAUD, 2004)

O nome "Luiza Ferreira" adveio de uma militante assassinada, no Estado de Pernambuco. Luiza Ferreira morreu em virtude da sua participação ativa em liderar ocupações de terras. Além do nome do assentamento ser de uma mulher que foi assassinada em decorrência da luta, há no assentamento estudado uma quantidade de mulheres que supera o número de homens. Para entender isso de forma mais ampla, fomos buscar dados no IBGE referentes à região. Contudo, não encontramos, nos dados deste Instituto, explicações numéricas que coubessem nesse fenômeno da presença feminina na luta por terra. As diferenças numéricas na Região da Zona da Mata, e nos Municípios de São Lourenço e Moreno são em torno de $5 \%$ para a maioria de mulheres em relação a de homens. Ainda assim, no Assentamento Luiza Ferreira, a diferença está em torno de $35 \%$ a mais de mulheres.

Por meio das entrevistas e dados disponibilizados pela secretária do Assentamento, foi constatado que 136 famílias compõem aquele assentamento. Algumas destas famílias, ainda, residem em suas antigas casas, em áreas periféricas de cidades vizinhas. Na participação da reunião semanal, na ata de presença, consta em média 100 assinaturas. E, o contingente de militantes para participar de protestos chega a preencher três ônibus com assentos para $5^{0}$ pessoas.

Há, em seus discursos, a produção de uma concordância, de ação social, em torno das mesmas questões. Este sentimento de que estão sendo representados em suas demandas consiste na grande articulação discursiva realizada pela proposta de um movimento social camponês que junte os trabalhadores do campo de todo o Brasil para ocupar terras como protesto político para erradicação da pobreza no Brasil. O signo "sem-terra" não é mais agregativo de indivíduos somente do campo. Já está presente nisso, a lógica da articulação e da hegemonia, defendidas por Laclau e Mouffe. Neste momento, este termo, "sem-terra", está esvaziado de um sentido único, pois comporta múltiplas e diferentes demandas (LACLAU \& MOUFFE, 2004). Contudo, no interior do Assentamento Luiza Ferreira, estes mesmos atores divergem no modo de organização de suas demandas. Este aspecto será melhor explicitado no tópico seguinte.

10 termo 'camponês' está sendo utilizado, aqui, para designar aquelas pessoas que vivem da agricultura familiar e, também, aquelas que se enquadram numa perspectiva de pluriatividade. Isto é, trabalhadores do campo que complementam suas rendas com outro vínculo trabalhista, não relacionado à sua atividade agrícola. Para tanto, nos referenciamos nos estudos de Maria Nazareth Baudel Wanderley (2003, 2009), José de Souza Martins (2003), Sonia Bergamasco (2003) e outros. Todos estes comungam da ideia, mais sistematicamente desenvolvida por Nazareth Wanderley, de que é possível constatar uma mudança no campo rural brasileiro e ela pode ser compreendida a partir do conceito de 'novas ruralidades': (i) é a modernização do rural, em termos de acessibilidade, aos bens de serviço produzidos no urbano; (ii) É o rompimento da dicotomia campo cidade. Ou seja, a concepção de que não há sociedade rural e sociedade urbana, mas uma sociedade com espaços diferenciados e peculiares; (iii) O rural é tornado num ator coletivo, onde transitam diversos interesses, conflitos e significados. Como, por exemplo, discurso em torno do meioambiente. Assim comenta, Wanderley: "Por outro lado, nas sociedades modernas o meio ambiente é a linguagem potencial de uma reconceitualização sociopolítica do rural [...] os atores rurais podem passar a assumir novas funções sociais, precisamente como mediadores entre a sociedade global e os espaços rurais”. (2009, p. 247). 


\section{A heterogeneidade do Assentamento: Atores, articulações e negações}

Dentro do Assentamento existem três instituições muito importantes a serem analisadas: a Igreja, a Associação de Mulheres e a Associação de Homens. No campo de pesquisa notamos que existe uma disputa entre as duas associações. A Associação das Mulheres foi criada e possui CNPJ desde 2013. Tem o objetivo de ascender socialmente por meio de estratégias particulares de produção coletiva, destacando as habilidades de trabalhos artesanais. Também desenvolvem cursos de bordados, pinturas e aulas de alfabetização. Além disso, reivindicam posicionamento legítimo em questões de ordem política relacionadas as questões das mulheres locais.

Por outro lado, a Associação de Homens reivindica sua organização pautada no princípio de que resguardam os interesses de todos os moradores do assentamento. Contudo, não tem nenhuma atividade específica por meio da qual escoam suas demandas. Isso sugere que esta associação não tenha definido, claramente, o seu regimento interno onde apontem as motivações e objetivos que a constitui. É possível que haja um receio de que as mulheres se sobreponham a eles, uma vez que elas estão na direção da associação e, também, da liderança do assentamento.

Quando comentado sobre o andamento da associação dentro de uma roda de conversa entre dois homens e duas mulheres, seguiu-se as seguintes ponderações:

\footnotetext{
PAULA SILVA: ... A associação das mulheres está cadastrada no CNPJ há mais de dois anos e tudo

MARIO SANTOS: Oxe! Eu posso virar mulher? É?! (Risos). Porque a associação delas está tão avançada que vou passar por lado delas.

FRANCINE SEVERINA: E se o senhor quiser entrar na associação da gente, não é só pra mulheres é para os homens também.

MARIO SANTOS: Eu não sei por que abriram outra associação! Porque já tem uma para os dois lados, para que abrir outra?! (...) A gente já está esperando chegar computadores, armário, um monte de coisa. A gente já ganhou muita doação. Só não chegaram ainda porque ainda não construímos uma sala para associação, ainda.

PESQUISADOR: Quando foi criada a associação dos homens?

PAULA SILVA: Começou esse ano. Não, não! Foi ano passado, eles deram entrada ano passado.

PESQUISADOR: Mas por que eles não se juntaram a vocês?

MARIA DE JESUS: Porque eles acham que a associação de mulheres não vai pra frente; Muita gente acha isso. Muita gente ainda diz assim: vocês ainda têm fé que essa associação vai dar certo? Então, eu digo que tenho e que vai dar tudo certo, porque a gente está lutando para subir na vida e vamos conseguir. E eu quero ver essa associação construída.
}

As mulheres relatam esse desinteresse dos homens, do assentamento, para as atividades que elas desenvolvem. De outro lado, os homens consideram suas reivindicações prioritariamente assentadas nas demandas de todos os/as moradoras/es. Sendo, portanto, desnecessário um segundo ator que dispute com eles as decisões tomadas. Esta concepção é habitada de uma tentativa de descredibilidade e ofuscação daquelas mulheres. Esse fenômeno aponta em duas direções: (i) de fato as ideias e sentidos são constituídos por uma disputa 
hegemônica; (ii) mecanismo de construção de uma invisibilidade por meio do descrédito das ações coletivas das mulheres. Este último ponto já nos coloca dentro de uma construção pós-colonial que desvela as identidades precárias e subalternas (SPIVAK, 2010).

O Terceiro ator, a Igreja pentecostal, acaba contribuindo para um apaziguamento entre as identidades divergentes. As mulheres, por exemplo, não estão posicionadas politicamente somente em relação à cooperativa. Os núcleos em que os assentados se organizam para pautar e debater as dificuldades locais e, também, a coordenação do acampamento, estão permeados da presença feminina. O próprio MST coloca essa forma de representação como princípio estrutural do movimento. Estas mulheres estão espalhadas na instância organizacional do assentamento dotadas de formação ideológica: base da organização cooperativa; cuidado com o meio ambiente e produção de alimentos orgânicos; busca da soberania alimentar. Contudo, a construção do assentamento é a própria reconstrução de suas vidas. Neste sentido, estas mulheres chegam até estes embates com o estoque cultural e marcas de ruptura institucionais de suas histórias de vida. Isto é, as outras experiências, entre elas a adesão religiosa, acompanham e também participam no processo de moldar a realidade social na qual estas militantes inscreverão os devidos sentidos de suas vidas. Essa constatação é bem percebida na busca de legitimação de seus papeis, naquele lugar. Várias mulheres atribuíram a conquista daquele lote de terra ao cumprimento da promessa de Deus, em sua vida. Neste caso, tomamos o cuidado metodológico de perceber a diferença entre estas afirmações e as afirmações comuns dos camponeses tradicionais que interpretam o mundo por meio da chave hermenêutica de sua tradição religiosa. Estas mulheres evidenciam que escutar "a revelação enviada por Deus" e, "a profecia da terra não se cumprirá sem luta”, são, por exemplo, estímulos emocionais importantes. Aqui elas não são só camponesas, são camponesas investidas de uma nova armadura política que é ampliada com os demais estímulos provocados pelo MST. Um encontro, uma disputa, uma simbiose temporária que confere um sentido pleno às suas existências. E sua experiência religiosa ocupa lugar central na forma como isso ocorrerá. A religião é estimuladora de um agenciamento, cujo centro é o pressuposto de que Deus provoca a alteração das circunstancias difíceis. Portanto, o quadro social é reformulado e suas estratégias de enfrentamento, também.

Lá, 80\% dos moradores são religiosos, inclusive todos da Convenção Geral da Assembleia de Deus, única igreja que faz cultos religiosos dentro do assentamento. No intuito de ganhar seguidores, semanalmente fazem culto no dia de sexta-feira nas casas dos religiosos, ou na plenária. Esta última foi construída pelos moradores para realizar reuniões relativas às decisões do Movimento. E durante outros dias da semana, são realizados cultos em outros assentamentos. Há, obviamente, um constante intercâmbio: alguns militantes frequentam estes cultos, bem como, recebem visitas desses outros companheiros de luta e de fé. Desde os primeiros estudos de sociologia, a religião já é percebida como uma instituição importante de ser analisada e compreendida na vida social. Durkheim (1989), por exemplo, já falou que o indivíduo que volta de uma experiência religiosa não é o mesmo. Ele está fortalecido de novas representações plausíveis sobre o mundo.

Neste sentido é que concordamos com José de Souza Martins (1999) e Bruno Comparato (2001) quando constataram que a Igreja é uma instituição relevante na produção ideológica do grupo. É por meio da fé, alimentada 
constantemente no interior dos cultos, que as camponesas pentecostais conseguem resistir à labuta diária de dificuldades pois, nutrem a esperança de que estão direcionadas conforme a vontade de Deus.

Desta maneira, percebemos que a religião pentecostal não reivindica para si uma hostilidade em relação ao MST. Pelo contrário, nestes ambientes, ela é também articulada para significar o cotidiano daqueles camponeses em esperança e fé de que vão, todos juntos, conquistar seu lote de terra. Veremos mais à frente, como essa articulação aparece no discurso das mulheres pentecostais. Além disso, pudemos aferir que a religião tende a ser um catalisador da ação política e que contribui para um diálogo menos hostil entre os atores internos. Esperamos explicitar melhor estas considerações, no tópico seguinte.

\section{A mulher pentecostal e a luta pela terra}

A religião, em particular o cristianismo, sempre demarcou espaços subalternos à mulher. Maria José Rosado-Nunes (2005) destaca que a religião é um campo de investimento masculino por excelência. Em sua perspectiva, os homens dominam a produção do que é sagrado e relegam a mulher à periferia dos espaços definidores da crença. Contudo, essa premissa observada historicamente não encontra correspondente no Assentamento Luiza Ferreira. Lá, $80 \%$ dos moradores são pentecostais e cerca de $70 \%$ dos pentecostais são mulheres. Tanto na liderança religiosa quanto na liderança política as mulheres estão mais organizadas, de maneira que há uma competição sutil entre as associações de homens e de mulheres. Os homens tentam desvalorizar os trabalhos das mulheres com a prerrogativa de que são trabalhos que produzem pouca ou nenhuma mudança. Com o argumento, por exemplo, de que só produzem trabalhos manuais, de borracha e pequenos enfeites. Tais críticas emergem dos homens não pentecostais. Pois aqueles que são ligados às mulheres pela mesma conduta religiosa tendem a ser cuidadosos na relação com a mulher, bem como na relação política de tomada da terra. Jaime Amorim, líder do MST em Pernambuco, já pontuou que os pentecostais são "disciplinados e aguerridos". Ele se referia a ausência de problemas conjugais pela ausência de vícios com jogos e bebidas alcoólicas. Neste sentido, o pentecostalismo no campo, tem sido interpretado como um fenômeno que fornece uma feição feminina, uma vez que a conversão exige uma conduta que será tanto mais genuína quanto houver preocupação na pacificidade familiar, preocupação com a educação dos filhos, por exemplo. Não é surpresa, portanto, que o MST tem interesse nos pentecostais do campo. Eles estão dispostos a lutar conjuntamente com as mulheres por uma igualdade social e, segundo Jaime Amorim, são mais propensos a repensar relações desiguais de poder, no âmbito familiar. De fato, essa é uma característica que deve ter regularidade, em condições análogas, em outros Estados do Brasil. Até o momento, entretanto, só podemos dizer que é uma característica peculiar do contexto do pentecostalismo nos assentamentos da Zona da Mata pernambucana.

As mulheres são duplamente empoderadas: pela doutrinação política do MST que defende uma igualdade de gênero e pela religião que impõe um papel profético como missão. Confiantes de que estão ali para subverter suas histórias que, sem exceção, são marcadas por abandono e violência, elas seguem com sua postura resiliente. Isto é, o papel da mulher pentecostal, naquele contexto, não é 
somente de sentinelas das práticas religiosas ou guardadoras da memória do grupo religioso. Cabem a elas, naquela configuração social, a fruição criativa para reinterpretar sua fé num diálogo constante com a política.

A maioria dos indivíduos que se identificam como pentecostais são mulheres. Essa mesma vantagem numérica feminina é observada no campo e, em particular, é bem expressiva no assentamento Luiza Ferreira. Isso contribui para a liderança feminina nas atividades pentecostais. Como não temos observado um distanciamento entre práticas religiosas e luta por terra no contexto da Zona da Mata pernambucana, são elas que conferem o pioneirismo e um rosto feminino ao pentecostalismo na reivindicação por terra.

\begin{abstract}
As histórias de conversão masculinas revelam situações de desemprego, dificuldades financeiras e problemas pessoais na área da saúde nas justificativas para a adesão religiosa ao pentecostalismo; já as mulheres quase sempre associam suas escolhas religiosas com as desavenças familiares e as necessidades - materiais e espirituais do grupo doméstico. Em outras palavras, enquanto os homens procuram a comunidade religiosa em situações que põem em ameaça a identidade masculina predominante na sociedade, as mulheres se colocam como guardiãs das almas de todos que integram a família, buscando os grupos confessionais sempre que um dos seus familiares se mostre em dificuldades. Nesse sentido, as qualidades alocadas ao gênero masculino no sistema hegemônico de representações parecem distanciar os homens das prescrições religiosas de uma forma geral e, em especial, do ethos pentecostal, enquanto os atributos femininos favorecem as experiências das mulheres com o sagrado e os vínculos com as comunidades religiosas. (MACHADO, 2005, p. 73)
\end{abstract}

Simone Beauvoir (1980, p. 56) já disse que no momento em que as mulheres começam a tomar parte na elaboração do mundo, esse mundo é ainda um mundo que pertence aos homens. Sustenta, também, que a mulher foi constituída como "o outro" do sexo masculino e isto a colocaria à mercê de suas decisões. Contudo, a mulher, segundo sua perspectiva, pode e deve reclamar sua existência política e isso será conquistado pela alteração num conjunto de instituições sociais e práticas culturais.

$\mathrm{Na}$ tentativa de desmistificar esse entendimento, o MST é um dos Movimentos que mais mobiliza Mulheres para a luta em todo Brasil. É uma organização que se propõe a reunir famílias para reivindicar, por meio de ocupações, a conquista da terra. Dentro do MST a atuação das mulheres nas lideranças nacionais, estaduais, regionais e municipais são bem notórias. Em 1980 foi organizada a Comissão Nacional de mulheres do MST, que estimula a uma participação mais afinca das mulheres dentro na militância do movimento. Em setembro de 1989, já na primeira edição das Normas gerais do MST, se incluiu um capítulo sobre a articulação das mulheres, com destaque para "a luta contra todas as formas de discriminação e contra o machismo", além de chamar a atenção para a necessidade de "organizar uma comissão de mulheres em nível nacional, responsável pelas políticas propostas para o movimento” (MST, 1989, Cap. VIII).

Em entrevista, Christiane Campos, coordenadora do Setor de Gênero do MST afirmou que as mulheres têm sido $30 \%$ da direção nacional. Em compensação afirma Deere que "depois da conquista da terra, nos assentamentos, um grande número de mulheres volta a fazer apenas trabalho interno, na roça, em casa ou com as crianças. Por isso, é necessário que as mulheres se organizem e participem da luta da classe trabalhadora em todas as instâncias" (DEERE, 2004, p. 186-187). Ou seja, ainda há um recuo político das mulheres na maior parte dos casos.

Em 1996 o MST criou uma cartilha sobre a questão da mulher no campo. No seu conteúdo há informações de que as mulheres sofrem discriminação nos 
acampamentos e assentamentos e que sentem ausência de estrutura que possibilitem a sua inserção nos trabalhos projetados pelo próprio movimento. A cartilha reconhece que isso trata-se de um problema de caráter político, uma vez que há uma assimetria nas relações de poder, de decisão, de participação. Desta maneira, através da organização de comissões e coletivos de mulheres do MST, se abancaram debates sobre o conceito de gênero e confecções de cartilhas a partir de meados dos anos 1990. Esta ação culminou na criação do Setor de Gênero realizada no Encontro Nacional do MST em 2000. Este evento trouxe um novo conceito e modo de discutir sobre a mulher. "Gênero passa a ser diferenciado de sexo, que é apresentado como característica biológica, relacionado à reprodução da espécie humana e, portanto, natural. Gênero passa a ser considerado uma construção social”. (GONÇALVES, 2005). Como resultado do empenho do Setor de gênero, a direção geral do MST decidiu que a mulher deve estar inserida em todas as instâncias da estrutura organizacional do movimento: no setor produtivo, na administração, no controle dos resultados. Segundo a direção, deve ser garantida que, em todos os núcleos de acampamentos e assentamentos, haja coordenador e coordenadora. Isso é bem perceptível no Assentamento Luiza Ferreira, pois as mulheres tomam cargos na Presidência e Vice-presidência da Associação das Mulheres, na Secretaria Geral do Assentamento e outros cargos internos.

Com essa quebra de paradigmas feita pelo MST na concepção sobre a mulher camponesa, a religião ainda procede sendo um sistema simbólico produtor de significados que assume função importante na vida das pessoas. Mulheres pentecostais entram na luta pela terra, se envolvendo com uma "nova concepção de mulher”. A questão fundamental é que a estrutura simbólica da religião tem influência no modo como as relações interpessoais são organizadas. A concepção de mulher que a Igreja Pentecostal tradicional propõe é vinculada definitivamente as características atribuídas a uma natureza feminina de sensibilidade e delicadeza que se contrapõem frontalmente à mulher que luta pela terra, que constatamos no Assentamento Luiza Ferreira. Esta última, participa de enfrentamentos e paralizações. São mulheres articuladoras de ações políticas. Portanto constata-se que há uma "nova mulher" pentecostal. Uma mulher que vive em meio a uma desconstrução de papeis posta pela igreja, sem deixar a crença e sem deixar a luta. E sim agregando e integrando concepções.

\section{A nova mulher pentecostal}

Nas entrevistas perguntamos a doze mulheres pentecostais sobre o que as levaram à participação no MST; se houve alguma mudança de vida posterior à sua chegada ao Assentamento; se elas participam de paralisações e passeatas; e se a religião da qual elas comungam tem algum posicionamento contra a inclusão delas no MST. A partir disso chegamos às seguintes constatações.

Motivos

Todas as entrevistadas afirmaram que é uma questão de necessidade econômica estarem participando do Assentamento na conquista de obter a sua terra, pois não tinham casa própria. Quatro delas se separaram do marido e tentaram conquistar a sua casa e seu sustento através da agricultura; duas moravam no antigo Engenho Bulhões antes do MST; outras sentiam o desejo de 
voltar para um ambiente rural para sustentar sua família por meio da agricultura familiar junto com seus respectivos maridos. E outros motivos mais específicos como cuidados com a saúde, uma vez que "podiam respirar ar puro".

Um dos depoimentos deve ser ressaltado. A camponesa pentecostal, aqui reconhecida como Maria Lira, disse que antes de ingressar no MST sentia-se dependente do marido e dos filhos. Também afirmou que se sente como uma nova mulher, pois participa de reuniões, nas quais a sua opinião é importante. $\mathrm{E}$, ainda mais, a sua convicção religiosa a fazia perceber que todas estas mudanças se configuravam como cumprimento das promessas de Deus em sua vida.

\section{Sonhos que forjam a mulher pentecostal}

Em especifico é analisado o discurso de um trio de mulheres pentecostais que alimentam a expectativa da "casa dos sonhos". A tão sonhada casa é de uma mulher que morava em São Paulo e foi deixada por seu marido. Conforme seu depoimento, ele não deu nenhuma justificativa, simplesmente partiu deixando com ela uma filha de dezoito anos. Sem saber para onde ir, essa mulher, aqui chamada de Ana de Deus, ingressou no movimento. Em entrevista, Ana de Deus e mais outra camponesa pentecostal - ambas se tratam como companheiras de luta - começaram a discorrer sobre suas vontades de realização no âmbito social. Elas afirmaram que criaram um vínculo entre elas e mais uma mulher, assim formando um trio; Uma é divorciada, outra é viúva, e Ana de Deus foi deixada pelo seu marido. Todas são mulheres pentecostais, conhecidas no assentamento como mulheres guerreiras, elas têm os mesmos objetivos, que é de sustentar sua família a partir da agricultura e construir suas casas. Na entrevista elas se emocionaram ao dizer que a conquista da terra é um marco muito importante para todas.

Num tem essa casinha de barro ai? (Nesse momento ela aponta para uma casa, deixando transparecer um sentimento de orgulho pelo feito). Fui eu que construí ela sozinha, era mato, e eu entrava na mata, buscava madeira sozinha pra construir ela. (Ana de Deus)

Nota-se que há uma emancipação da mulher. As circunstâncias fizeram delas sujeitos engajados na luta, sem ter a presença de um homem acompanhando-as na realização de suas necessidades fundamentais e imediatas. Pelo contrário, elas avançaram na compreensão de que contam umas com as outras para manter a conquista da casa própria. Compreendem também que esta configuração é o resultado de suas insistências na oração. De modo que, em reiteradas assertivas acerca do presente e numa releitura de suas histórias pessoais, diziam não precisar de um homem para conquistar seus objetivos. "Seguir a Deus e ter força nos braços" era a frase síntese de suas histórias. Com isso, segundo seus depoimentos, conseguiriam concretizar os seus sonhos.

\section{Religião e Política}

Como havíamos mencionado anteriormente a concepção das mulheres que a Igreja propõe está vinculada a características atribuídas a uma natureza feminina de sensibilidade e delicadeza que é paradoxal à identidade da mulher camponesa pentecostal que luta pela terra. 
É notável que, dentro do Assentamento Luíza Ferreira, há mulheres pentecostais engajadas que vive em meio a uma desconstrução de papeis. Nas entrevistas constatamos através dos seus discursos que existe um envolvimento entre a religião e o MST muito intrínseco, de modo que elas não reproduziram ideologias avessas entre sua crença e o movimento. Ou seja, elas reelaboram as suas práticas, de tal forma que elas não enxergam conflitos entre a religião e a militância. É bem verdade que elas estão hegemonizadas pelo discurso da terra, porém os aspectos religiosos são suscitados para fortalecimento na militância.

A maioria daquelas militantes participa dos cultos. Dirigem a parte musical, pregam, lideram grupos de oração, são professoras das classes dominicais de jovens e crianças, dentre outras atividades. Falas deixam exposta:

\footnotetext{
De manhã eu ia pra oração porque tinha consagração, por que primeiro a gente faz a devoção pra poder trabalhar. Porque é Deus que dá força, coragem e saúde. Em nome de Jesus! (Elizabeth da Cruz)
}

Participo de protesto, passeata, fecho a BR mas eu não fico no meio do pessoal que briga. A gente faz uma passeata pacifica mas se os policiais vim, tem gente que vai em cima mas eu me saio. Eu não brigo. (Josefa Maria)

Estas mulheres pentecostais e sem-terra sinalizam para uma fé cuja face pública é de engajamento político. Uma das entrevistadas, Dona Severina, disse que Deus havia revelado por meio do pastor de sua Igreja, quando ela ainda morava no bairro do Ibura, em Recife, que aquela terra seria dela. E que ela não podia desistir da luta, pois desta forma alcançaria a benção prometida. Outro exemplo, é da militante Elizabeth que é formada em Teologia, é cantora evangélica e líder do núcleo de direitos humanos do MST. Em vários momentos, Elizabeth demonstra uma criatividade em articular saberes do MST com saberes bíblicos. Como a palavra de ordem2 usada pelo MST: "se o campo não planta, a cidade não janta”. Em seu discurso, há uma relação disso com uma, possível, missão de Deus que é reorientar sua vida pela produção da terra e pela dignidade que essa conquista possibilita. Aquelas mulheres percebem seu papel social desde o lugar de camponesa, pobre e sem-terra. Além disso, também é problematizada a relação de um contexto de acumulo de capital e latifúndio em detrimento de grande número de camponeses em situação de restrições várias de vida. Óbvio que o MST ajuda na concatenação de todos estes discursos agregativos, de modo que continuem fazendo sentido num contexto belicoso. Mas, são mulheres que possuem mais uma ferramenta cabal para responder à situação de subalternidade que tentam reproduzir sobre elas, na luta pela terra. Essa ferramenta é constituída claramente pelo aporte de sua experiência religiosa pentecostal. afirmou:

Há, também, algumas contradições. Umas das participantes da entrevista

Participo de enfrentamentos, mas sei que Deus não se agrada disso, porque somos diferentes e lá a gente entra em conflito com aqueles policiais e Deus não gosta”. (Joana Assis)

No entanto ela continua exercendo sua participação na igreja e ao mesmo tempo no movimento. E vale salientar que foram 12 mulheres entrevistadas e só

2 O termo 'palavra de ordem' é utilizado nos atos políticos realizados pelo MST. É uma sentença que transmite com o uso mínimo da linguagem a ideologia e motivos daquela ação especifica. Também ajuda a entender a palavra de ordem num contexto de produção social a seguinte definição: "A unidade elementar da linguagem - o enunciado - é a palavra de ordem. (...) A ordem não se relaciona a significações prévias, nem com uma organização prévia de unidades distintivas, mas sim o inverso. A informação é apenas o mínimo estritamente necessário para a emissão, transmissão e observação das ordens consideradas como comandos” (DELEUZE \& GUATARRI, 1995, p. 11 apud GOMES, 2003, p. 92). 
1 demostrou não ter feito essa ligação entre fé e militância por terra de maneira harmoniosa. No entanto todas elas seguem com suas crenças sem deixar a luta política pela mudança de suas vidas.

\section{Considerações Finais}

Neste trabalho pudemos perceber que: (i) O Assentamento Luiza Ferreira é caracterizado como um espaço heterogêneo. Isto é: há uma diversidade de atores e de interesses que se antagonizam pela disputa de sentido; (ii) $\mathrm{O}$ discurso ideológico do MST, de fato, no contexto estudado, produz um empoderamento das mulheres na labuta cotidiana; (iii) constatamos que no contexto de inserção, construção e associações que ocorrem no interior do assentamento, as mulheres pentecostais produzem uma hermenêutica própria, na qual a militância é percebida como um propósito de Deus para suas vidas.

Há uma hermenêutica própria onde não tem uma instituição dizendo o sentido da vida. Aquelas mulheres interpretam a vida e produz um sentido a partir da síntese dos discursos religioso e político. Elas conseguem transitar entre estes discursos sem perceber transgressão de seu modo de fé. Logo, a maioria delas sente que não quebra a regra de Deus e nem as dos homens. Elas juntam a religião e política e reelaboram as suas práticas religiosas. A política de gênero do MST empodera e a religião, também. Ambas são catalizadoras de um novo sujeito: a mulher pentecostal que luta por terra no bojo dos processos de luta pela reforma agrária do MST.

\section{Referências bibliográficas}

BAUER, Martin W; GASKEL, George; ALLUM, Nicholas C. Pesquisa Qualitativa com texto, imagem e som: um manual prático. Petrópolis: Vozes, 2002.

BEAUVOIR, Simone de. O segundo sexo: Fatos e Mitos. 8.ed. Rio de Janeiro: Nova Fronteira, 1980. v. 1.

BERGAMASCO, Sonia M.P.P.; NORDER, Luiz A.C. A alternativa dos assentamentos rurais: organização social, trabalho e política. Campinas: FAEP/Terceira Margem, 2003.

BERGAMASCO, Sônia M.P.P.; COSTA, Cyra M. O. Processo de Organização da Produção em Assentamentos Rurais no Brasil: a fazenda Pirituba/SP In: BERGAMASCO, Sonia M. P. P; AUBRÉE, Marion; FERRANTE, Vera L. S. B. (orgs). Dinâmicas familiar, produtiva e cultural nos assentamentos rurais de São Paulo. Campinas: FEAGRI/UNICAMP, 2003, p. 213-194.

BURITY, Joanildo A. Religião e lutas identitárias por cidadania e justiça: Brasil e Argentina. Ciências Sociais Unisinos, v. 45-3, p. 183-195, 2009. 
CAMPOS, Leonildo Silveira. As origens norteamericanas do pentecostalismo brasileiro: observações sobre uma relação ainda pouca avaliada. Revista USP: Dossiê Religiosidade no Brasil, São Paulo, no 67, p. 104, set-nov, 2005.

COMPARATO, Bruno Konder. Ação Política do MST. São Paulo: Expressão Popular, 2001.

CORTEN, André. Os pobres e o Espírito Santo: o pentecostalismo no Brasil. Petrópolis: Vozes, 1996, p. 62.

D'EPINAY, Christian Lalive. O refúgio das massas: estudo sociológico do protestantismo Chileno. Rio de Janeiro: Paz e Terra, 1970.

DURKHEIM, Émile. As formas elementares da vida religiosa: o sistema totêmico na Austrália. São Paulo: Paulus, 1989, ed. 2.

FILGUEIRAS, Fernando de Barros. Guerreiro Ramos, a redução sociológica e o imaginário pós-colonial. Cad. $C R H$, Salvador, v. 25, n. 65, p. 347-363, ago. 2012. Disponível

em <http://www.scielo.br/scielo.php?script=sci_arttext\&pid=So10349792012000200011\&lng=pt\&nrm=iso $>$. Acesso em 07 jul. 2016. http://dx.doi.org/10.1590/So103-49792012000200011.

FLICK, Uwe. Uma introdução à pesquisa qualitativa. Ed 2. Porto Alegre: Bookman, 2009.

GOMES, Mayra Rodrigues. Palavra de Ordem/Dispositivo Disciplinar. Galáxia, n. 5, abril, 2003, p. 91-108.

GONÇALVES HONÓRIO, R. (2005). Acampamentos: novas relações de gênero (con)fundidas na luta pela terra do Pontal do Paranapanema. In: Lutas Sociais, $n^{\circ} 13 / 14$.

HOWARTH, David; NORVAL, Aletta J.; STAVRAKAKIS, Yannis. Discourse theory and political analysis: identities, hegemonies and social change. Oxford: Manchester University Press, 2000.

LACLAU, Ernesto. La razón populista. Buenos Aires: Fondo de Cultura Econômica de Argentina S.A, 2005.

LACLAU, Ernesto; MOUFFE, Chantal. Hegemonia y estratégia socialista: hacia uma radicalización de la democracia. Argentina: Fondo de Cultura Econômica, 2004.

MACHADO, Maria das Dores Campos. Representações e relações de gênero nos grupos pentecostais. Rev. Estud. Fem., Florianópolis , v. 13, n. 2, p. 387396, ago. 2005.

MARIANO, Ricardo. Neopentecostais: sociologia do novo pentecostalismo no Brasil. São Paulo: Edições Loyola, 1999.

MARTINS, José de Souza. O cativeiro da terra. $7^{\mathrm{a}}$ ed. São Paulo: Hucitec, 1998. 
. O poder do atraso: ensaios de sociologia da história lenta. São Paulo: Hucitec, 1999, $2^{\mathrm{a}}$ ed.

. (org.). Travessias: a vivência da reforma agrária nos assentamentos. Porto Alegre: UFRGS Editora, 2003.

MOUFFE, Chantal. Em torno a lo político. Buenos: Fondo de cultura Economica de Argentina AS, 2007.

. Democracia, cidadania e a questão do pluralismo. In: Política $e$ Sociedade, $\mathrm{n}^{\mathrm{O}}$ 3, out. 2003, p. 11-26.

NOGUEIRA, Amauri T. Barbosa; SUZUKI, Júlio César. Conflitos e estratégias de luta no Assentamento da Fazenda Jupira. In: Anais do II Encontro de Grupos de Pesquisa, Uberlândia, 20-22/jun. 2006, p. 1-14.

ROSADO-NUNES, Maria José. Gênero e religião. Rev. Estud. Fem., Florianópolis, v. 13, n. 2, p. 363-365, ago. 2005.

SIGAUD, Lygia. As condições de possibilidades da ocupação da terra. Revista Tempo Social, 2004.

SOUZA, Jesse. Em defesa da Sociologia: o economicismo e a invisibilidade das classes sociais. In: Revista Brasileira de Sociologia, v. 1, n. 1, p. 127-158, 2013.

WANDERLEY, Maria de Nazareth Baudel. Agricultura familiar e campesinato: rupturas e continuidade. In: Estudos de Sociologia, n. 21, Rio de Janeiro: CPDA, 2003.

O mundo rural como um espaço de vida: reflexões sobre a propriedade da terra, agricultura familiar e ruralidade. Porto Alegre: UFRGS Editora, 2009. 